\title{
Astigmatism Management with Astigmatism- Correcting Intraocular Lens Using Two Toric Calculators - A Comparative Case Series
}

\author{
Yu-Te Huang' \\ Chun-Ju Lin (D) $1-3, *$ \\ Chun-Ting Lai ${ }^{1, *}$ \\ Ning-Yi Hsia (D) \\ Peng-Tai Tien ${ }^{1,4}$ \\ Henry Bair ${ }^{1,5}$ \\ Huan-Sheng Chen (iD) ${ }^{6}$ \\ Chun-Chi Chiang ${ }^{1,2}$ \\ Jane-Ming Lin ${ }^{1,3}$ \\ Wen-Lu Chen ${ }^{1,3}$ \\ Wen-Chuan Wu' \\ Yi-Yu Tsai $^{\text {I-3 }}$ \\ 'Department of Ophthalmology, China \\ Medical University Hospital, China \\ Medical University, Taichung, Taiwan; \\ ${ }^{2}$ School of Medicine, College of Medicine, \\ China Medical University, Taichung, \\ Taiwan; ${ }^{3}$ Department of Optometry, Asia \\ University, Taichung, Taiwan; ${ }^{4}$ Graduate \\ Institute of Clinical Medical Science, \\ College of Medicine, China Medical \\ University, Taichung, Taiwan; ${ }^{5}$ Stanford \\ University School of Medicine, Stanford, \\ CA, USA; ${ }^{6}$ An-Shin Dialysis Center, \\ NephroCare Ltd., Fresenius Medical \\ Care, Taichung, Taiwan \\ *These authors contributed equally to \\ this work
}

Correspondence: Chun-Ju Lin; Chun-Ting Lai

Department of Ophthalmology, China Medical University Hospital, 2 Yuh-Der Road, Taichung City, 40447, Taiwan

Tel +886-4-22052121, ext. 1141

Fax +886-4-22059265

Email doctoraga@gmail.com;

withwind037@yahoo.com.tw
Background: To compare refractive outcomes after phacoemulsification and toric IOL implantation using two different toric calculators for initial astigmatism assessment in a realworld setting.

Methods: This was a retrospective, comparative, interventional case series. Patients over 30 -year-old who underwent phacoemulsification and toric IOL implantation (AcrySof ${ }^{\circledR}$ Toric IOL) by the same surgeon between 2017 and 2018 were included. Eyes with irregular astigmatism, previous corneal refractive surgery, intraocular surgery, corneal pathology, macular pathology and pupil abnormalities were excluded. IOL toricity was determined by using a calculator provided by the AcrySof Toric calculator before 2018 and Barrett Toric Calculator after 2018. Patient demographics, corneal topography, vector and preoperative and postoperative refraction were collected and analyzed at three months postoperative.

Results: Thirty-two eyes of 32 patients were included in the final analysis. 0.1D for surgically induced astigmatism was used. Group 1 included 14 eyes assessed with the original (AcrySof) toric IOL calculator, and group 2 included 18 eyes assessed with the Barrett toric IOL calculator. In group 1 , postoperative astigmatism less than $-1.00 \mathrm{D},-0.75 \mathrm{D}$, and $-0.5 \mathrm{D}$ was achieved in $88.2 \%, 76.1 \%$ and $53.7 \%$ of eyes, respectively, while, in group 2, 89\% eyes achieved postoperative residual astigmatism less than $0.5 \mathrm{D}$ and all eyes achieved postoperative residual astigmatism less than $0.75 \mathrm{D}$. The proportion of patients with lower postoperative astigmatism was significantly higher in Group 2 ( $p<0.05$ by chi-square test), a pattern that still held when we divided patients into multiple groups. Vector analysis with the Alpins methods also supported better outcomes in the Barrett group (0.71 D vs $0.35 \mathrm{D})$.

Conclusion: The Barrett Toric calculator resulted in better results in the prediction of residual astigmatism than original (AcrySof) toric calculators.

Keywords: astigmatism, cataract surgery, toric intraocular lens, posterior corneal astigmatism

\section{Background}

In cataract patients with astigmatism, using toric IOLs in cataract surgery treats cataracts and astigmatism in one procedure and results in better postoperative visual quality. ${ }^{1}$ Nevertheless, they require additional effort, including preoperative measurement, planning, and modifications in intraoperative techniques. ${ }^{2-7}$ Previous $^{2}$ studies have reported good visual and refractive outcomes, which are an important part of the standard of care for astigmatism correction with cataract surgery, especially in higher degrees of astigmatism. ${ }^{8-12}$ This procedure is also ideal for 
patients with regular astigmatism who hope to reduce their dependence on glasses for distance vision.

Unfortunately, in real-word practice, this is not always the cases, with "refractive surprise" still present from time to time. ${ }^{13}$ Variations in refractive outcomes of toric IOLs stem from several factors, including imperfections in anterior corneal surface measurement and alignment of toric IOL, corneal surgical-induced astigmatism (SIA), and disparities in the formulas used to calculate IOL power. ${ }^{9-11,14}$

Early toric calculators (eg, AcrySof Toric calculator) led to variable results, with only $50-75 \%$ of eyes exhibiting postoperative astigmatism of $-0.50 \mathrm{D}$ or less. ${ }^{4}$ The Barrett Toric IOL calculator theoretically accounts for posterior corneal astigmatism (PCA) and effective lens position (ELP), which may lead to more accurate preoperative prediction of residual astigmatism. ${ }^{15}$ It is the first formula to provide non-inferior and reliable predictions based on measurements of posterior corneal curvature.

Therefore, we conducted a retrospective, comparative, interventional case series to compare refractive outcomes after standard $2.2 \mathrm{~mm}$ clear corneal phacoemulsification and toric IOL implantation using either the original (AcrySof) Toric calculator or Barrett Toric IOL calculator.

\section{Methods}

A retrospective, comparative, interventional case series was conducted. The study was approved by an institutional review board Institutional review board approval was obtained from the China Medical University Hospital. This study was conducted in compliance with Good Clinical Practices (GCPs) and was consistent with the 1996 version of the Declaration of Helsinki.

Inclusion criteria were patients over 30-years-old with a follow-up period of more than three months. The subjects were diagnosed with cataracts but otherwise had good ocular health. Detailed preoperative evaluation including dilated indirect fundoscopy and OCT were performed in all patients to screen out those with retinal pathology. Patients also had regular corneal astigmatism between $1.00 \mathrm{D}$ and 5.00D. Eyes with irregular astigmatism identified by corneal topography were excluded. To limit confounding variables, all eyes with previous corneal refractive surgery, intraocular surgery, corneal pathology, maculopathy and pupil abnormalities were excluded. Any subjects who experienced complications during surgery were also excluded. All eyes underwent standard $2.2 \mathrm{~mm}$ clear corneal phacoemulsification and toric IOL implantation (AcrySof ${ }^{\mathbb{B}}$ Toric IOL, Alcon Laboratories, Inc.,
Fort Worth, TX) between July, 2017 and June, 2018 by the same surgeon (Lin CJ). Automated keratometry, IOL Master 700 biometry (Carl Zeiss Meditec, Jena, Germany), and Pentacam (OCULUS, Wetzlar, Germany) were used as measurement methods in undilated eyes. Repeated measurements were performed and the value with repeatability was chosen. Also, patients with dry eye were pre-treated before biometry measuring.

The A standardized corneal refractive index 1.3375 was used. SIA magnitude value was set at 0.10 diopter (Table 1). The IOL toricity was determined with the AcrySof Toric calculator for patients treated before 2018 and Barrett Toric Calculator for patients treated after 2018. The online AcrySof-Barrett Toric Calculator was used to plan the axis of placement and cylinder power for the toric IOL with a printout of the toric calculator results made available at operation room.

The eye was marked with the patient in the upright position; this was performed with the patient fixating with the contralateral eye at a distant target at head height to avoid cyclotorsion from near-fixation under topical anesthesia, and the limbus was then marked at the desired angle of alignment using a needle and a surgical marking pen.

All operations were performed by the same surgeon using a two-plane, 2.2-mm incision placed just anterior to the limbus in the axis of the clear cornea. Following a divide-and-conquer nucelofractis and irrigation / aspiration for cortex removal, a toric IOL was implanted. The surgical wound was closed with stromal hydration. Levofloxacin 5mg/mL (Cravit, Santen Pharmaceutical Co., Osaka, Japan) and prednisolone acetate $1.0 \%$ eye drops were given 4 times daily for 2 weeks.

Patient demographics, corneal topography, and preoperative and postoperative refraction were collected before

Table I Centroid Surgically Induced Astigmatism Used in Barrett Toric Calculator

\begin{tabular}{|l|c|c|c|c|}
\hline Centroid & \multicolumn{2}{|c|}{ OS } & \multicolumn{2}{c|}{ OD } \\
\hline Incision & SIA (D) & Number & SIA (D) & Number \\
\hline Nocation & & & & \\
Supal & 0.17 & 3 & 0 & 0 \\
Superior temporal & 0 & 0 & 0 & 0 \\
Temporal & 0 & 0 & 0.38 & 1 \\
Inferior temporal & 0 & 0 & 0.17 & 6 \\
Inferior & 0 & 0 & 0 & 0 \\
Overall SIA & 0.17 & 3 & 0 & 0 \\
\hline
\end{tabular}


and 3 months after surgery. The results from using the original (AcrySof) and Barrett Toric IOL calculator were compared.

\section{Vector Analysis}

The overall accuracy of astigmatism correction was calculated with the Alpins vector analysis method at 3 months after operation. ${ }^{16}$ AstigMATIC software was used for this analysis. ${ }^{17}$ The software included three astigmatism parameters: preoperative, target (set as 0), and achieved astigmatism. Four standard graphs were produced: 1) Target-Induced Astigmatism Vector (TIA), 2) Surgically Induced Astigmatism Vector (SIA), 3) Difference Vector (DV), and 4$)$ Correction Index (CI). ${ }^{17}$

\section{Statistical Analysis}

For statistical evaluation, SPSS for Windows (Version 13.0; SPSS Inc., Chicago, Illinois, USA) was used. Descriptive statistics on univariate data were performed in histogram. Chi-square test was used for residual astigmatism comparison between the two different toric calculators.

\section{Results}

In total, 32 eyes of 32 patients were collected. All operations were performed by the same surgeon. Group 1 included 14 eyes from 14 patients (4 males and 10 females) assessed with the original (AcrySof) Toric IOL calculator. The mean age was $65.2 \pm 12.2$ years (range, $37-80$ ). Figure 1 showed the cumulative result of the two group. $14.3 \%$ of eyes achieved postoperative residual astigmatism less than $-0.25 \mathrm{D}$. $57.2 \%$ of eyes achieved less than $-0.5 \mathrm{D}$ and $64.3 \%$ of eyes achieved less than $-0.75 \mathrm{D}$; only $78.6 \%$ of eyes had residual astigmatism less than $-1.00 \mathrm{D}$.

Group 2 included 18 eyes from 18 patients $(7$ males and 11 females) assessed with the Barrett Toric IOL calculator. The mean age was $67.6 \pm 7.7$ years (range, 5384). $50 \%$ of eyes achieved postoperative residual astigmatism less than $-0.25 \mathrm{D}$. $88.9 \%$ of eyes achieved postoperative residual astigmatism less than $-0.5 \mathrm{D}$, and $100 \%$ of eyes achieved postoperative residual astigmatism less than $-0.75 \mathrm{D}$ and $-1.00 \mathrm{D}$. (Figure 1).

The proportion of patients with lower postoperative astigmatism was significantly higher in Group $2(\mathrm{p}<0.05$ by chi-square test), a pattern than held when we divided patients into multiple groups (postoperative astigmatism cylinder $\geq-0.25 \mathrm{D},-0.25 \mathrm{D}>$ cylinder $\geq-0.5 \mathrm{D},-0.5 \mathrm{D}>$ cylinder $\geq-0.75 \mathrm{D},-0.75 \mathrm{D}>$ cylinder $\geq-1 \mathrm{D})$ and into binary groups (postoperative astigmatism cylinder $\geq-0.5 \mathrm{D}$ and $<$ $-0.5 \mathrm{D}$; cylinder $\geq-0.25 \mathrm{D}$ and $<-0.25 \mathrm{D}$ ) (Figure 2 ).

Figures 3 and 4 show the results of the vectorial astigmatism analysis at 3 months of follow-up. Figure 3 displays the vector analysis in Group 1 (AcrySof Toric IOL calculator.) while Figure 4 demonstrates the analysis in Group 2 (Barrett toric IOL calculator.) Mean TIA were similar in both groups $(2.39 \mathrm{D}$ vs $2.43 \mathrm{D})$. Mean DV, which represents the remaining astigmatism and provides

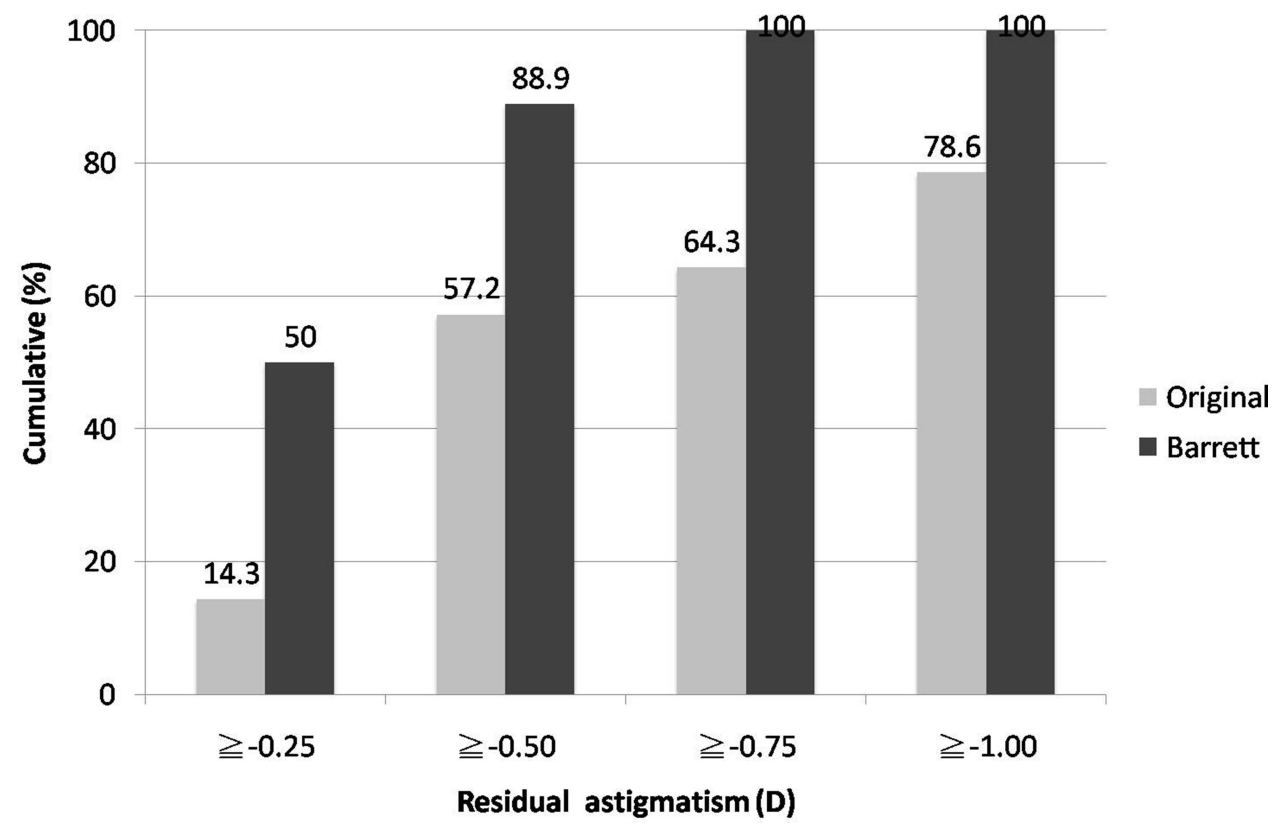

Figure I Cumulative percentage of postoperative residual astigmatism analysis using original and Barrett toric IOL calculator. 

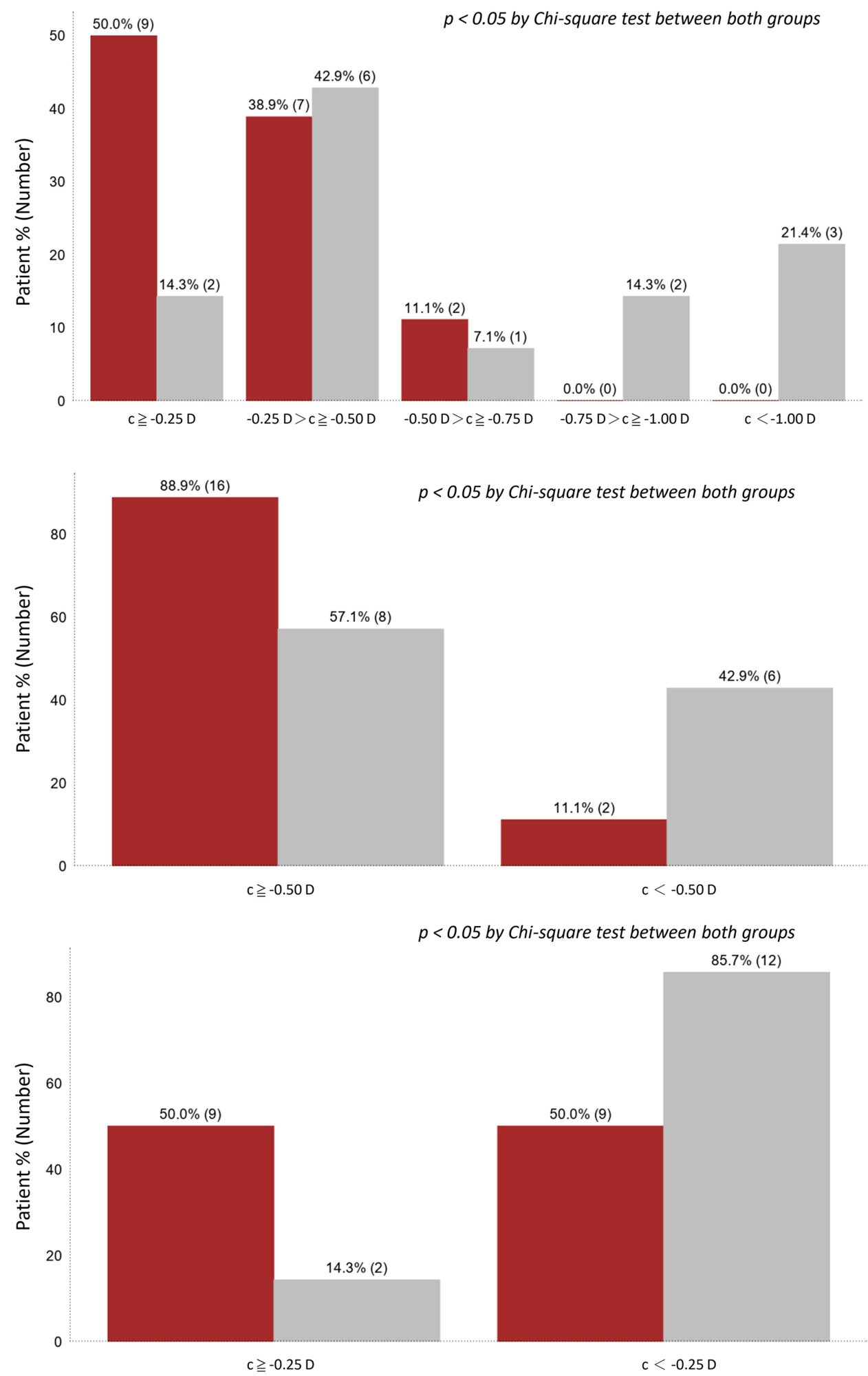

Two Groups of Patients with Different Residual Astigmatism by Ranges

Barrett Toric IOL calculato

Original Toric IOL calculator c: cylinder

Figure 2 The proportion of patients with lower postoperative astigmatism is significantly higher in Group 2 ( $p<0.05$ by chi square test), no matter we divided patients in multiple groups (postoperative astigmatism cylinder $\geq-0.25 \mathrm{D},-0.25 \mathrm{D}>$ cylinder $\geq-0.5 \mathrm{D},-0.5 \mathrm{D}>$ cylinder $\geq-0.75 \mathrm{D},-0.75 \mathrm{D}>$ cylinder $\geq-\mathrm{ID}$ ) or in binary groups (postoperative astigmatism cylinder $\geq-0.5 \mathrm{D}$ and $<-0.5 \mathrm{D}$; cylinder $\geq-0.25 \mathrm{D}$ and $<-0.25 \mathrm{D}$ ). 


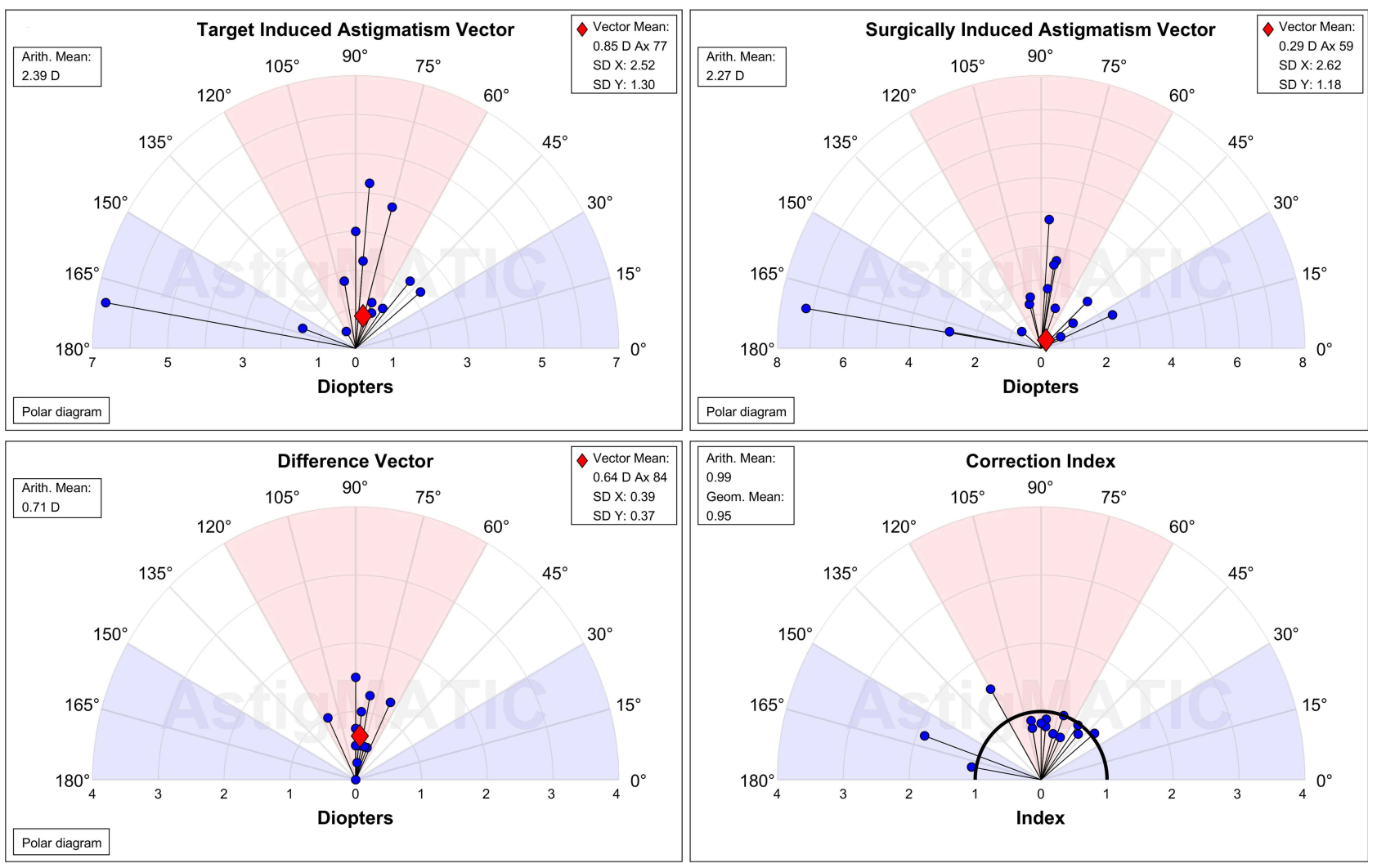

Figure 3 Vector analysis by the Alpins method of astigmatism changes in Group I (AcrySof Toric IOL calculator). Abbreviations: Arith mean, arithmetic mean; Ax, Axis.

a summary of the astigmatic error, showed better results in the Barrett group (0.71 D vs $0.35 \mathrm{D})$. In CI, which demonstrates the under- $(<1)$ or overcorrection $(>1)$ of astigmatism treatment, revealed both these two calculators were slightly under-corrected (0.99 vs 0.93 ).

\section{Discussion}

With the recognition of the importance of posterior corneal astigmatism, new toric calculators were developed and have greatly helped with lowering post-operative astigmatism. In our study, the differences we found between the older calculator and the Barrett Toric calculator were larger than expected, with statistical significance reached in all parameters $(\mathrm{p}<0.05$ by chi-square test) (Figure 2$)$. The old AcrySof calculator used simulated $\mathrm{K}$ values generated by a fixed cornea model of $500 \mu \mathrm{m}$ thickness and anterior/ posterior radius of $0.82,{ }^{18}$ which was shown in our study to be less precise in reflecting the overall corneal astigmatism.

The posterior surface of most corneas is steep vertically, approximately $0.26-0.78 \mathrm{D}$ in previous studies, causing against-the-rule (ATR) refractive astigmatism. ${ }^{13,19}$
Previous generations of toric calculator (eg, AcrySof Toric calculator), which ignored the posterior corneal surface, would over-correct eyes with with-the-rule (WTR) astigmatism and under-correct eyes with ATR astigmatism.

Due to person-to person variability, it is important to measure PCA individually so for a more precise astigmatism correction. This could be done by the incorporation of measured PCA from swept-source OCT such as with IOL Master 700 (Carl Zeiss Meditec, Jena, Germany), or topographic Scheimpflug analysis, such as the with Pentacam (OCULUS, Wetzlar, Germany). However, whether measured PCA is significantly better than predicted PCA is still worth further investigation. Skrzypecki et al did not find any statistically significant difference in residual astigmatism when using the Barrett Toric Calculator incorporating either the measured PCA (with IOL master 700) or predicted PCA, ${ }^{20}$ but Kingrey et al found that $14 \%$ of cases ended up with a different toric IOL selection with the Barrett toric calculator. ${ }^{21}$

Our study showed comparable results with previous studies. Generally, prospective studies reveal relatively better 


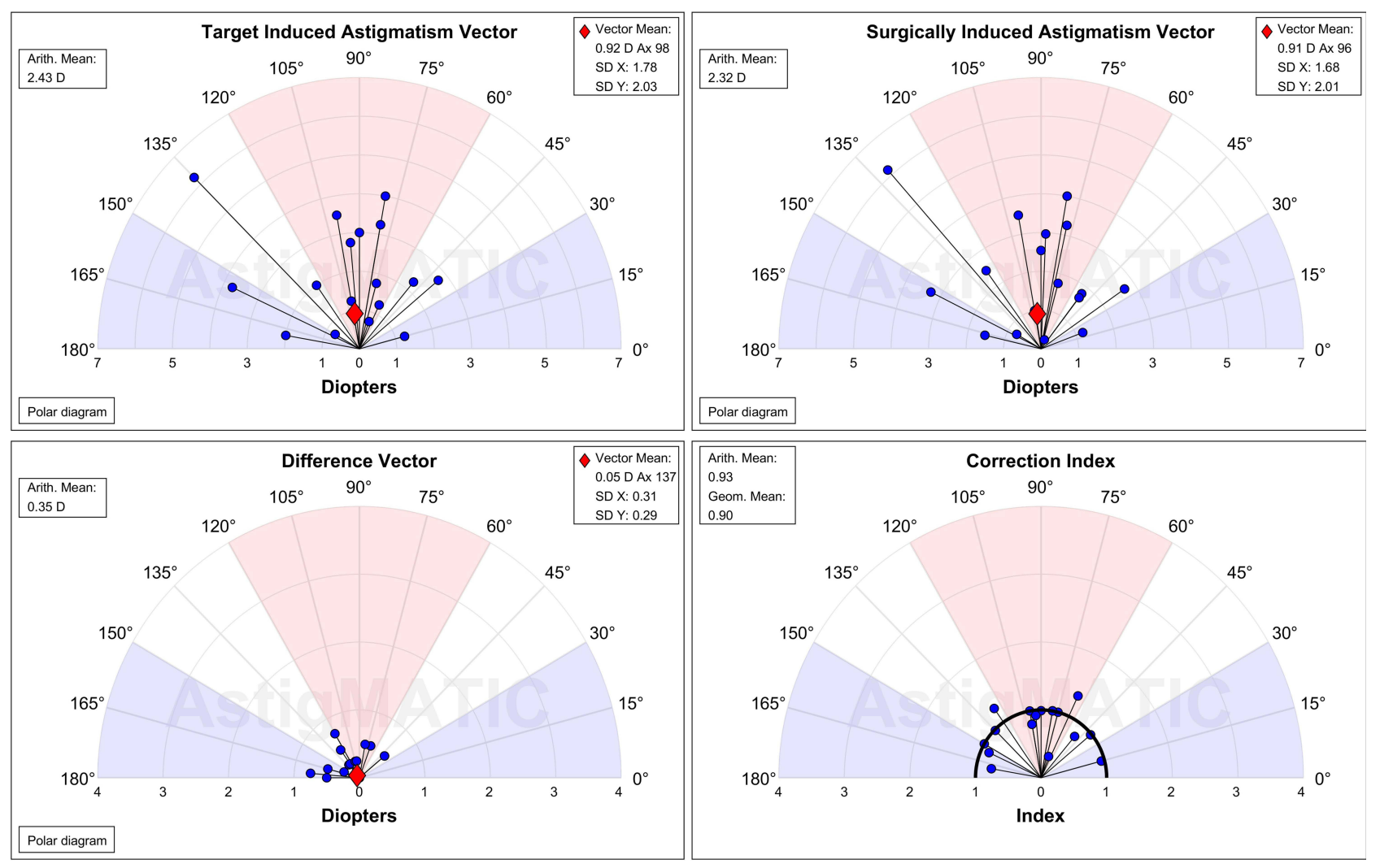

Figure 4 Vector analysis by the Alpins method of astigmatism changes in Group 2 (Barrett toric IOL calculator). Abbreviations: Arith mean, arithmetic mean; Ax, Axis.

outcomes then retrospective studies due to its nature. But retrospective designs were much closer to daily clinical practice from some aspects. A recent large dataset came from a retrospective 823 cases series by Kane and Connell, revealing $88.2 \%, 76.1 \%$ and $53.7 \%$ of eyes had a post absolute prediction error less than $-1.00 \mathrm{D},-0.75 \mathrm{D}$, and $-0.50 \mathrm{D}$, respectively, using Barrett Toric calculator. ${ }^{22}$ In other prospective studies the results were slightly better, with 96.7 to $100 \%, 83.9 \%$ to $100 \%$ and 75 to $96 \%$ of eyes with a post absolute prediction error less than $-1.00 \mathrm{D},-0.75 \mathrm{D}$, and $-0.50 \mathrm{D}$, respectively. ${ }^{10,12,18,23}$ In our study, $100 \%, 100 \%$ and $88.9 \%$ of eyes had postoperative residual astigmatism less than $-1.00 \mathrm{D},-0.75 \mathrm{D}$, and $-0.50 \mathrm{D}$, respectively.

With the Alpins vector analysis method, our studies showed slightly larger values of under-correction in the Barrett calculator group (Correction index 0.99 vs 0.93 ). In further analyses, we found that there was one outlier value in this group causing the deviation. It was $-0.75 \mathrm{D}$ in before operation and $-0.5 \mathrm{D}$ after operation. Although the definite value was small, it accounted for a large proportion of the CI value.
The regression algorithms based on population mean values in the Barrett Toric calculator estimates posterior corneal astigmatism from anterior corneal astigmatism. As the result, the best possible anterior surface astigmatism measurements should be emphasized. We suggest the following clinical practice: first, perform at least two measurements with different devices (in our practice: IOL Master 700 and Pentacam). Then, repeat topography and ensure that all measurements closely match. Finally, re-evaluate the corneal surface if there are ambiguous results. We demonstrate that good preoperative measurements, combined with an advanced toric calculator such as the Barrett Toric calculator, are capable of achieving $-0.50 \mathrm{D}$ or less of residual refractive astigmatism $90 \%$ of the time in real-world clinical practice.

The limitations of this study include its retrospective nature and the small sample size. In Taiwan, patients pay extra fees of astigmatism-correcting intraocular lenses out of pocket. Nevertheless, overlooking the contribution of the posterior cornea might not make a huge difference in the outcome for the patients. However, selection of an IOL calculator that considers posterior corneal astigmatism and SIA may improve refractive outcomes. 


\section{Conclusions}

In conclusion, the Barrett Toric calculator, which includes consideration of PCA and SIA, was found to have lower median absolute errors in the prediction of residual astigmatism than the original toric calculator in our present study. The Barrett Toric calculator helps minimize postoperative variation after toric IOL implantation and a high percentage of eyes had a residual refractive astigmatism of $-0.5 \mathrm{D}$ or less. Prospective randomized studies are necessary to further validate our findings.

\section{Abbreviations}

ATR, Against-the-rule; BCVA, Best-corrected visual acuity; ELP, Effective lens position; IOL, Intraocular lens; OCT, Optical coherence tomography; PCA, Posterior corneal astigmatism; SIA, Surgically induced astigmatism; WTR, With-the-rule.

\section{Data Sharing Statement}

The datasets used and/or analysed during the current study are available from the corresponding author on reasonable request.

\section{Ethics Approval and Consent to Participate}

The study protocol described here was approved by the Institutional Review Board of China Medical University Hospital and conformed to the tenets of the Declaration of Helsinki.

\section{Consent for Publication}

Owing to the retrospective design of the study and the use of deidentified patient information, the review board waived the need for written informed consent.

\section{Funding}

No funding was used for the design and conduction of this study.

\section{Disclosure}

The authors have no proprietary, commercial, or noncommercial interest in any materials mentioned in this article. The authors report no conflicts of interest in this work.

\section{References}

1. Hashemi H, Fotouhi A, Yekta A, Pakzad R, Ostadimoghaddam H, Khabazkhoob M. Global and regional estimates of prevalence of refractive errors: systematic review and meta-analysis. J Curr Ophthalmol. 2018;30:3-22. doi:10.1016/j.joco.2017.08.009

2. Davison JA, Makari S, Potvin R. Clinically relevant differences in the selection of toric intraocular lens power in normal eyes: preoperative measurement vs intraoperative aberrometry. Clin Ophthalmol. 2019;13:913-920. doi:10.2147/OPTH.S205352

3. Goggin M, van Zyl L, Caputo S, Esterman A. Outcome of adjustment for posterior corneal curvature in toric intraocular lens calculation and selection. $J$ Cataract Refract Surg. 2016;42:1441-1448. doi:10.1016/j.jcrs.2016.10.004

4. Visser N, Bauer NJ, Nuijts RM. Toric intraocular lenses: historical overview, patient selection, IOL calculation, surgical techniques, clinical outcomes, and complications. J Cataract Refract Surg. 2013;39:624-637. doi:10.1016/j.jcrs.2013.02.020

5. Ventura BV, Wang L, Weikert MP, Robinson SB, Koch DD. Surgical management of astigmatism with toric intraocular lenses. Arq Bras Oftalmol. 2014;77:125-131. doi:10.5935/0004-2749.20140032

6. Ferreira TB, Ribeiro P, Ribeiro FJ, O’Neill JG. Comparison of astigmatic prediction errors associated with new calculation methods for toric intraocular lenses. J Cataract Refract Surg. 2017;43:340-347. doi:10.1016/j.jcrs.2016.12.031

7. Kaur M, Shaikh F, Falera R, Titiyal JS. Optimizing outcomes with toric intraocular lenses. Indian J Ophthalmol. 2017;65:1301-1313. doi:10.4103/ijo.IJO_810_17

8. Mohammad-Rabei H, Mohammad-Rabei E, Espandar G, et al. Three methods for correction of astigmatism during phacoemulsification. J Ophthalmic Vis Res. 2016;11:162-167. doi:10.4103/2008-322X. 183924

9. Lake JC, Victor G, Clare G, Porfírio GJ, Kernohan A, Evans JR. Toric intraocular lens versus limbal relaxing incisions for corneal astigmatism after phacoemulsification. Cochrane Database Syst Rev. 2019;12:CD012801.

10. Núñez MX, Henriquez MA, Escaf LJ, et al. Consensus on the management of astigmatism in cataract surgery. Clin Ophthalmol. 2019;13:311-324. doi:10.2147/OPTH.S178277

11. Kessel L, Andresen J, Tendal B, Erngaard D, Flesner P, Hjortdal J. Toric intraocular lenses in the correction of astigmatism during cataract surgery: a systematic review and meta-analysis. Ophthalmology. 2016;123:275-286. doi:10.1016/j.ophtha.2015.10.002

12. Solomon KD, Sandoval HP, Potvin R. Correcting astigmatism at the time of cataract surgery: toric IOLs and corneal relaxing incisions planned with an image-guidance system and intraoperative aberrometer versus manual planning and surgery. J Cataract Refract Surg. 2019;45:569-575. doi:10.1016/j.jcrs.2018.12.002

13. Koch DD, Ali SF, Weikert MP, Shirayama M, Jenkins R, Wang L. Contribution of posterior corneal astigmatism to total corneal astigmatism. J Cataract Refract Surg. 2012;38:2080-2087. doi:10. 1016/j.jcrs.2012.08.036

14. Yeu E, Cheung AY, Potvin R. Clinical outcomes of toric intraocular lenses: differences in expected outcomes when using a calculator that considers effective lens position and the posterior cornea vs one that does not. Clin Ophthalmol. 2020;14:815-822. doi:10.2147/OPTH. S247800

15. Barrett G. Barrett toric formula; 2018. Available from: http://calc. apacrs.org/toric_calculator20/ToricCalculator.aspx. Accessed June 01, 2021

16. Alpins N. Astigmatism analysis by the Alpins method. $J$ Cataract Refract Surg. 2001;27:31-49. doi:10.1016/S0886-3350(00)00798-7

17. Gauvin M, Wallerstein A. AstigMATIC: an automatic tool for standard astigmatism vector analysis. BMC Ophthalmol. 2018;18:255. doi:10.1186/s12886-018-0920-1 
18. Yang J, Zhang H, Yang XT, Tian F, Zhao SZ. Accuracy of corneal astigmatism correction with two Barrett Toric calculation methods. Int J Ophthalmol. 2019;12:1561-1566. doi:10.18240/ijo.2019.10.07

19. Piñero DP, Caballero MT, Nicolás-Albujer JM, de Fez D, Camps VJ. A new approach for the calculation of total corneal astigmatism considering the magnitude and orientation of posterior corneal astigmatism and thickness. Cornea. 2018;37:720-726. doi:10.1097/ ICO.0000000000001577

20. Skrzypecki J, Sanghvi Patel M, Suh LH. Performance of the Barrett Toric Calculator with and without measurements of posterior corneal curvature. Eye (Lond). 2019;33:1762-1767. doi:10.1038/s41433-0190489-9
21. Kingrey BS, Kingrey D. Posterior corneal astigmatism for toric IOL calculations: a comparison between the Barrett Toric Calculator predicted astigmatism versus direct posterior corneal measurement with a Scheimpflug camera. Invest Ophthalmol Vis Sci. 2020; 61:1672.

22. Kane JX, Connell B. A comparison of the accuracy of 6 modern toric intraocular lens formulas. Ophthalmology. 2020;127:1472-1486. doi:10.1016/j.ophtha.2020.04.039

23. Clark KD. Toric intraocular lens outcomes with a new protocol for IOL selection and implantation. $J$ Fr Ophthalmol. 2018;41:145-151. doi:10.1016/j.jfo.2017.08.007
Clinical Ophthalmology

\section{Publish your work in this journal}

Clinical Ophthalmology is an international, peer-reviewed journal covering all subspecialties within ophthalmology. Key topics include: Optometry; Visual science; Pharmacology and drug therapy in eye diseases; Basic Sciences; Primary and Secondary eye care; Patient Safety and Quality of Care Improvements. This journal is indexed on PubMed

Submit your manuscript here: https://www.dovepress.com/clinical-ophthalmology-journal
Dovepress

Central and CAS, and is the official journal of The Society of Clinical Ophthalmology (SCO). The manuscript management system is completely online and includes a very quick and fair peer-review system, which is all easy to use. Visit http://www.dovepress.com/ testimonials.php to read real quotes from published authors. 